\section{Inhibition of the asthmatic allergen challenge response by the CRTH2 antagonist OC000459}

\author{
Dave Singh*, Paul Cadden*, Michael Hunter\#, Lisa Pearce Collins", Mike Perkins*, \\ Roy Pettipher", Elizabeth Townsend ${ }^{\#}$, Shân Vinall ${ }^{\#}$ and Brian O’Connor ${ }^{\text {I, }}+$
}

ABSTRACT: CRTH2 (chemoattractant receptor expressed on T-helper (Th) type 2 cells) is a Gprotein-coupled receptor expressed by Th2 lymphocytes and eosinophils that mediates prostaglandin $(P G) D_{2}$-driven chemotaxis. We studied the efficacy of the oral CRTH2 antagonist OC000459 in steroid-naïve asthmatic patients.

A randomised, double-blind, placebo-controlled, two-way crossover study of 16 days' treatment with OC000459 (200 mg twice daily) on the late (LAR) and early (EAR) asthmatic responses to bronchial allergen challenge was conducted, with 16 subjects completing the study.

There was a $25.4 \%(95 \% \mathrm{CI} 5.1-45.6 \%)$ reduction in the LAR area under the curve (AUC) for change in forced expiratory volume in $1 \mathrm{~s}$ with OC000459 compared with placebo $(p=0.018)$ but no effect on the EAR. Sputum eosinophil counts at 1 day post-allergen challenge were lower after OC000459 treatment $(p=0.002)$. $P_{2} D_{2}$-induced blood eosinophil shape change ex vivo was assessed at day $7(n=7)$. The AUC of eosinophil shift for OC000459 was lower than placebo; the mean difference was $-33.6 \%(95 \% \mathrm{Cl}-66.8--0.4 \%$; $p=0.048)$.

OC000459 treatment inhibited LAR and post-allergen increase in sputum eosinophils. This CRTH2 antagonist appears to inhibit allergic inflammation in asthma.

KEYWORDS: Asthma, chemokine, eosinophil, late allergic response

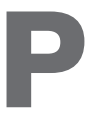

rostaglandin (PG) $\mathrm{D}_{2}$ is a product of arachidonic acid metabolism that is secreted predominantly by mast cells [1] but also by T-helper cell (Th) type 2 lymphocytes [2]. Levels of $\mathrm{PGD}_{2}$ are raised in the airways of patients with asthma after allergen challenge [3], suggesting a role for this prostanoid in promoting Th2-mediated allergic inflammation. CRTH2 (chemoattractant receptor expressed on Th2 cells) is a G-proteincoupled receptor expressed by Th2 lymphocytes, eosinophils and basophils that mediates chemotaxis and activation of these cells in response to $\mathrm{PGD}_{2}[4]$. CRTH2 antagonists inhibit the activation and chemotaxis of lymphocytes, eosinophils and basophils in vitro [2,5], and reduce airway inflammation in animal models of allergic inflammation [6]. These data suggest that inhibition of CRTH2 can suppress allergic inflammation in asthma.

OC000459 is an N1-indole acetic acid derivative that is a potent and selective antagonist of CRTH2. This drug has been shown to improve pulmonary function in patients with asthma [7]. The aim of this study was to investigate the ability of OC000459 to inhibit allergic airway responses in patients with asthma. We performed a double-blind, placebocontrolled, crossover study in steroid-naïve asthma patients to assess the effectiveness of OC000459 using inhaled allergen challenges.

\section{METHODS}

\section{Subjects}

21 corticosteroid-naïve patients with physiciandiagnosed asthma were recruited. Subjects were required to be aged 18-45yrs and have been nonsmokers for $\geqslant 6$ months with a $<10$ pack-yr history. Corticosteroid use was not allowed within $\geqslant 12$ weeks prior to screening. Patients were recruited by advertising in the media and within primary care. At screening, patients were required to have a forced expiratory volume in $1 \mathrm{~s}$ (FEV1) $>65 \%$ predicted, have a positive skin test to either house dust mite, grass pollen or cat allergen, and to demonstrate both an early and late asthmatic reaction to one of these allergens when inhaled. Subjects were also required to have haematology and biochemistry values within the normal ranges. All patients provided written informed consent. The study was approved by the local research ethics committee (West Midlands Research Ethics
AFFILIATIONS

*University of Manchester, Medicines Evaluation Unit, University Hospital of South Manchester Foundation Trust, Wythenshawe, \#Oxagen Ltd, Abingdon, 'Dept of Asthma, Allergy and Respiratory Science, Guy's, King's and St Thomas' School of Medicine at King's College Hospital, and ${ }^{+}$Respiratory Clinical Trials, London, UK.

CORRESPONDENCE

$P$. Cadden

University of Manchester

Medicines Evaluation Unit

University Hospital of South

Manchester Foundation Trust

Wythenshawe

Manchester

M23 9QZ

UK

E-mail: pcadden@doctors.org.uk

Received:

May 312011

Accepted after revision:

March 122012

First published online:

April 102012

European Respiratory Journal

Print ISSN 0903-1936

Online ISSN 1399-3003 
Committee), and was registered at clinicaltrials.gov with identifier number NCT01056692.

\section{Study design}

This was a two-centre, double-blind, randomised, placebocontrolled, crossover study. Eligible subjects were randomised to receive OC000459 $200 \mathrm{mg}$ orally twice daily or matching placebo for 16 days, in addition to inhaled salbutamol as required. The washout period was 3 weeks between treatment periods. The measurement of vital signs (heart rate and blood pressure) and FEV1 during the treatment periods are shown in table 1 ; these measurements were performed pre-dose on days 1 , $8,15$ and 16, while exhaled nitric oxide fraction ( $F \mathrm{eNO})$ was performed pre-dose on days 1,8 and 15. Pre-dose blood sampling was performed for the measurements of biochemistry and haematology at days 1, 8 and 15, with pharmacokinetics also measured on days 8 and 15 . Seven subjects provided blood samples for the measurement of eosinophil shape change up to $8 \mathrm{~h}$ post-dose on day 8 . An inhaled allergen challenge was performed on day 15 at $3 \mathrm{~h}$ post-dose. On day 16, a methacholine challenge was performed at $3 \mathrm{~h}$ post-dose, followed by induced sputum; methacholine challenge and induced sputum were therefore performed $24 \mathrm{~h}$ post-allergen challenge.

\section{Allergen and methacholine challenges}

Bronchial challenges were performed as we have previously described [8] using a Mefar Dosimeter (Mefar, Bologna, Italy). Allergen for skin-prick tests (Soluprick SQ; Alk Abelló (UK) Ltd, Reading, UK) was stored at $4^{\circ} \mathrm{C}$; each subject was assessed for sensitivity to house dust mite, cat, grass pollen, and positive and negative controls. The allergen for inhalation was selected according to the largest skin test wheal (positive $>3 \mathrm{~mm}$ ) and clinical history. Fresh solutions of allergen were made up in $0.9 \%$ saline in doubling concentrations from 250 standardised quality units $(\mathrm{SQ}-\mathrm{U}) \cdot \mathrm{mL}^{-1}$ to $32,000 \mathrm{SQ}-\mathrm{U} \cdot \mathrm{mL}^{-1}$. At screening, incremental doses of allergen were inhaled until an early asthmatic response (EAR) was observed, defined as a fall in FEV1 of $\geqslant 20 \%$ from the post-saline value, on at least one occasion, 5-30 min after the final concentration of allergen. The late asthmatic response (LAR) was defined as a fall in FEV1 of $\geqslant 15 \%$ from the post-saline value, on at least three occasions, two of which must be consecutive, $4-10 \mathrm{~h}$ after the final

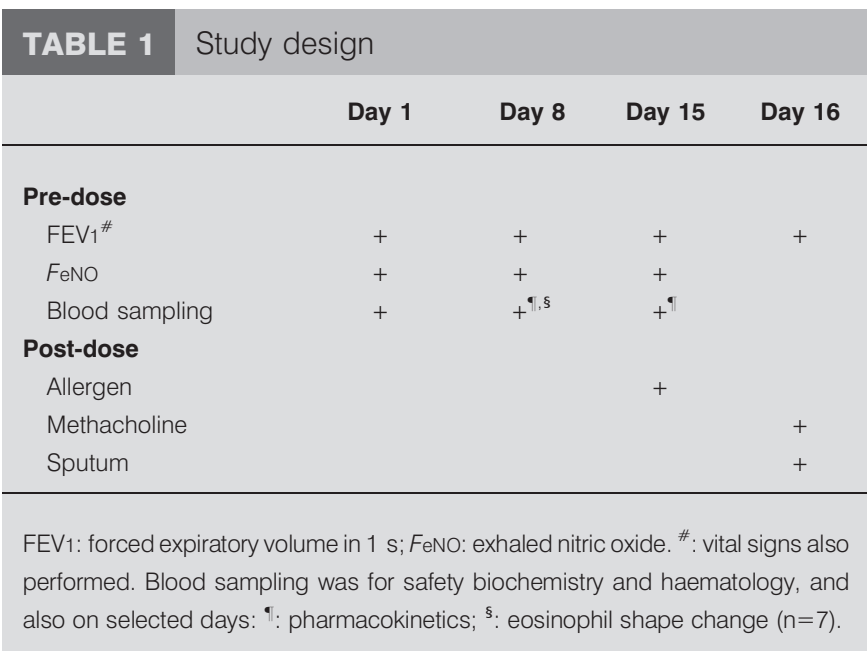

concentration of allergen. During the treatment periods, the total dose of allergen required to cause an EAR and LAR was administered as a single bolus dose.

Methacholine challenges were performed as previously described [8].

\section{Exhaled nitric oxide fraction}

FeNO was measured using the Ecomedics AG analyser CLD 88 (Duernten, Switzerland) at a flow of $50 \mathrm{~mL} \cdot \mathrm{s}^{-1}$. Three acceptable readings were recorded from each subject and the mean was used for analysis.

\section{Induced sputum}

Sputum was induced using 3\%, 4\% and 5\% saline, inhaled in sequence for $5 \mathrm{~min}$ via an ultrasonic nebuliser (Ultraneb 2000; Medix, Harlow, UK). Sputum was selected from the saliva and processed with dithiothreitol within $2 \mathrm{~h}$ of collection as previously described [9]. Cytospin preparations were air dried, fixed with methanol and stained with Rapi-diff (Triangle, Skelmersdale, UK). Slides were considered inadequate and discarded if 400 leukocytes were not able to be counted due to an excessive amount of squamous cell contamination. Leukocytes were counted and the results expressed as a percentage of the total leukocyte count and a total cell count per gram.

\section{Pharmacokinetic analysis}

Blood samples were taken into 2-mL plastic (Vacutainer) tubes containing lithium heparin pre-cooled to $4^{\circ} \mathrm{C}$. Blood samples were kept on water ice and were centrifuged at about $2,500 \times g$ for $10 \mathrm{~min}$ at $4^{\circ} \mathrm{C}$, within $15 \mathrm{~min}$ of collection. The resulting plasma was transferred to polypropylene vials and immediately frozen at $<-20^{\circ} \mathrm{C}$ until transferred to BioDynamics Research Ltd (Rushden, UK). The concentration of OC000459 in plasma was determined using a validated liquid chromatography-tandem mass spectrometry bioanalytical method. In brief, the analytical method involved liquid-liquid extraction followed by analysis of the extracts using a liquid chromatograph-tandem mass spectrometer equipped with a Turbolonspray (AB Sciex, Concord, Canada) interface. The mass spectrometer was operated using multiple reaction monitoring in the positive ion detection mode. A stable isotope internal standard was used. The lower limit of quantification for OC000459 in plasma was $1 \mathrm{ng} \cdot \mathrm{mL}^{-1}$. Values below this level were reported as below lower limit of quantification. Samples that gave results above the calibration range (upper limit $400 \mathrm{ng} \cdot \mathrm{mL}^{-1}$ ) were diluted 10 -fold with plasma prior to re-analysis.

\section{Eosinophil shape change}

This assay was performed in all the subjects participating at one centre $(n=7)$, using the method described previously [10]. Blood samples $(2 \mathrm{~mL})$ were collected into heparinised Vacutainers for measurement of $\mathrm{PGD}_{2}$-induced eosinophil shape change predose and at 2, 4, 6 and $8 \mathrm{~h}$ after dosing on day 8 . $\mathrm{PGD}_{2}$ (Biomol, Plymouth Meeting, PA, USA; in a volume of $0.001 \mathrm{~mL}$ ) at a concentration of $10 \mathrm{nM}$ was added to $0.2 \mathrm{~mL}$ heparinised blood in duplicate and incubated for $60 \mathrm{~min}$ at $37^{\circ} \mathrm{C}$. $0.3 \mathrm{~mL}$ Cytofix buffer (BD Biosciences, Oxford, UK) was added and left on ice for $15 \mathrm{~min} .4 \mathrm{~mL}$ red blood cell lysis buffer (Gentra Systems, Minneapolis, MN, USA) was added, incubated for $5 \mathrm{~min}$ at room temperature and then centrifuged at $300 \times g$ for $5 \mathrm{~min}$. The lysis step was repeated with a 10-min incubation and cells 
resuspended in $0.25 \mathrm{~mL} \mathrm{RPMI} / 10 \%$ fetal calf serum. A fluorescence-activated cell sorter (FACS; BD FACSCalibur) was used to measure forward scatter of eosinophils, which were separated from neutrophils by their autofluorescence. The percentage of eosinophils showing shape change in response to $\mathrm{PGD}_{2}$ over $8 \mathrm{~h}$ are presented.

\section{Statistical analysis}

The primary efficacy end-point was the inhibition of the LAR as measured by the area under the curve (AUC) and the maximum percentage changes in FEV1 between 4 and $10 \mathrm{~h}$ after allergen challenge. This study had $80 \%$ power with 16 completed subjects to detect a $40 \%$ attenuation of the LAR AUC by OC000459 relative to placebo. Secondary end-points included the inhibition of the EAR measured by the AUC and the maximum percentage changes in FEV1 $0-2 \mathrm{~h}$ after allergen challenge, sputum eosinophil percentage and the number of cells per gram sputum after allergen challenge, methacholine provocative concentration causing a 20\% fall in FEV1 (PC20) after allergen challenge, FeNO and FEV1 pre-dose on days 8 and 15. The EAR and LAR data were analysed using a mixed model with period, sequence group, centre and treatment as fixed effects, and subject as a random effect. The treatment by centre interaction was included in an initial model but was not statistically significant and so was dropped from the final model. Results from the mixed models are presented as adjusted values for placebo and OC000459 with the estimated treatment difference (with 95\% confidence intervals (CI)) and p-value. Non-parametric data was log-transformed for analysis (\% eosinophils, FeNO, methacholine PC20) using similar mixed models as for the LAR FEV1; the results were back-transformed and presented as adjusted geometric means for OC000459 and placebo, and the differences between placebo and OC000459 presented as a ratio of geometric means (with 95\% CI). A square root transformation was used for the number of eosinophils (and data were not back-transformed). For induced sputum, the data from subjects able to produce sufficient sputum in both treatment arms were used. Eosinophil shape change analysis was performed using a mixed model as for the LAR FEV1.

\section{RESULTS}

51 subjects were screened, with 21 found to be eligible and enrolled into the study; the demographics of these subjects are shown in table 2. Only seven of these 21 subjects produced adequate sputum samples at screening; these sputum cell counts are shown in table 1 . Two subjects decided to withdraw consent for the study at the end of the first treatment period, while one subject had to be withdrawn as scheduling of treatment period 2 was not possible. One subject was withdrawn by the investigator as the FEV1 had fallen below $65 \%$ pred on the morning of the allergen challenge in the second treatment period, while another subject was withdrawn due to the development of a viral infection. Adverse events were reported in 13 (65\%) subjects during treatment with OC000459 and 14 (74\%) subjects during placebo treatment. There was no difference between the treatment periods in the type of events reported, which were mainly respiratory tract infections and symptoms of asthma. There were no effects of OC000459 on blood haematology or biochemistry. The efficacy end-points were analysed in the 16 subjects who completed the entire study.

\begin{tabular}{|c|c|c|}
\hline TABLE 2 & \multicolumn{2}{|c|}{$\begin{array}{l}\text { Subject demographics and baseline sputum cell } \\
\text { counts }\end{array}$} \\
\hline \multicolumn{2}{|l|}{ Age yrs } & $31.1 \pm 7.1$ \\
\hline \multicolumn{2}{|c|}{ Males/females $n / n$} & $18 / 3$ \\
\hline \multicolumn{2}{|c|}{ FEV 1 L } & $3.62 \pm 0.8$ \\
\hline \multicolumn{2}{|l|}{ FEV $_{1} \%$ pred } & $87.4 \pm 12.0$ \\
\hline \multicolumn{2}{|l|}{ FeNO ppb } & $32.7 \pm 21.8$ \\
\hline \multicolumn{2}{|c|}{ Methacholine $\mathrm{PC}_{20} \mathrm{mg} \cdot \mathrm{mL}^{-1}$} & $1.48 \pm 3.2$ \\
\hline \multicolumn{2}{|c|}{ Sputum total cell count $\times 10^{6}$ cells $\cdot \mathrm{g}^{-1}$ sputum } & $0.96 \pm 0.4$ \\
\hline \multicolumn{2}{|c|}{ Sputum neutrophils $\%$} & $42.0 \pm 26.6$ \\
\hline \multicolumn{2}{|c|}{ Sputum macrophages $\%$} & $41.7 \pm 23.2$ \\
\hline \multicolumn{2}{|c|}{ Sputum eosinophils \% } & $6.0(1.5-23.9)$ \\
\hline \multicolumn{2}{|c|}{ Sputum Iymphocytes \% } & $2.7 \pm 3.1$ \\
\hline
\end{tabular}

Data presented as mean \pm SD or geometric mean $(95 \% \mathrm{Cl})$, unless otherwise stated. FEV1: forced expiratory volume in $1 \mathrm{~s}$; \% pred: \% predicted; FeNO: exhaled nitric oxide fraction; $\mathrm{PC} 20$ : provocative concentration causing a $20 \%$ fall in FEV1.

\section{Allergen challenge}

OC000459 reduced the LAR on day 15 (fig. 1), significantly inhibiting the fall in FEV1 AUC (25.4\% inhibition compared to placebo, 95\% CI 5.1-45.6\%; $\mathrm{p}=0.018$ ). The effect of OC000459 on the maximum percentage change in FEV1 approached statistical significance (3.9\% inhibition compared to placebo, 95\% CI -0.3$8.1 \% ; \mathrm{p}=0.065$ ). FEV1 on day 16 (at $24 \mathrm{~h}$ post-allergen challenge) was significantly lower $(\mathrm{p}=0.001)$ after placebo $(2.92 \mathrm{~L}) \mathrm{com}$ pared to OC000459 (3.18 L). There was a significant reduction in FEV1 on day $16(\mathrm{p}<0.001)$ compared to pre-allergen challenge FEV1 on day 15 after placebo treatment, but no change after OC000459.

There was evidence of a period effect $(\mathrm{p}=0.015)$, as patients receiving OC000459 in the second treatment period (sequence $\mathrm{A}, \mathrm{n}=7$ ) had a mean $43 \%$ inhibition of LAR AUC, while patients receiving OC000459 in the first treatment period (sequence $\mathrm{B}$, $n=9$ ) had only $0.9 \%$ inhibition of LAR AUC; the FEV1 changes by sequence are shown in figure 2 . The LAR during the screening visit is also shown in figure 2; the screening and

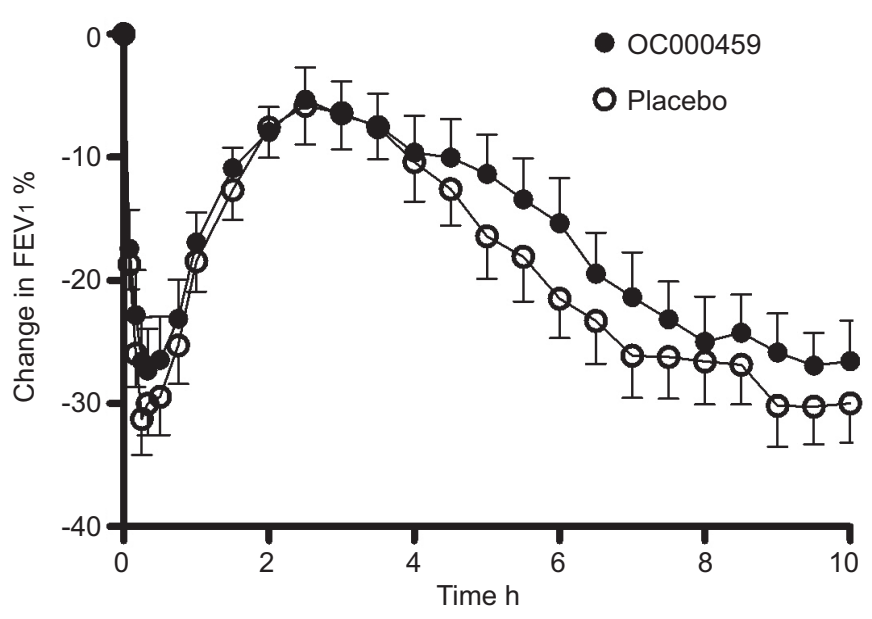

FIGURE 1. Reduction in forced expiratory volume in $1 \mathrm{~s}$ (FEV1) during allergen challenge after treatment with OC000459 or placebo. 


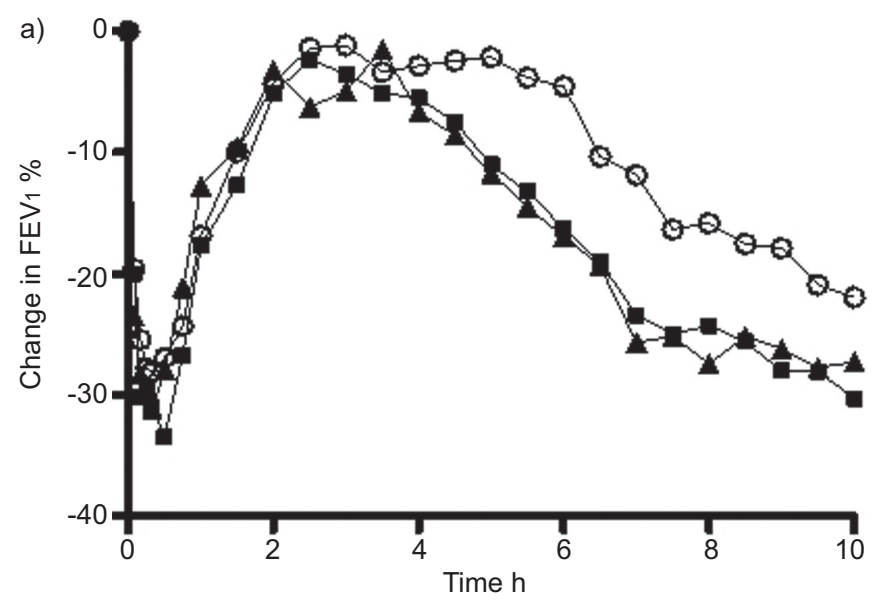

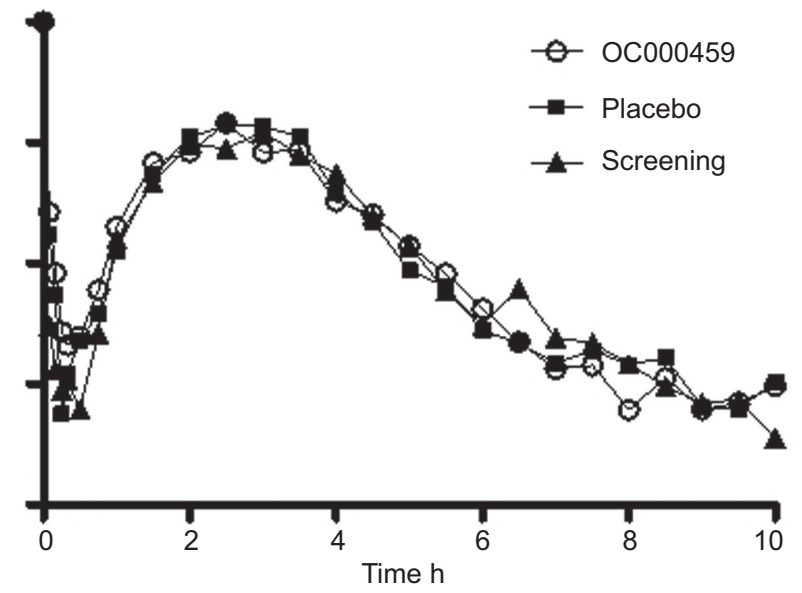

FIGURE 2. Reduction in forced expiratory volume in $1 \mathrm{~s} \mathrm{(FEV1)} \mathrm{during} \mathrm{allergen} \mathrm{challenge} \mathrm{on} \mathrm{a)} \mathrm{sequence} \mathrm{A}$ (first treatment period placebo; second treatment period OC000459) and b) sequence B (first treatment period OC000459; second treatment period placebo).

placebo challenge data were very similar in both sequences. This indicates that a "carry-over" effect did not occur in sequence B. The LAR AUCs during sequence A were $106.3 \% \cdot h$ and $166.0 \% \cdot h$ for OC000459 and placebo, respectively, while corresponding values during sequence B were $211.0 \% \cdot h$ and $210.7 \% \cdot h$, respectively. This suggests a greater allergic response for patients in sequence B, as the AUCs for the placebo treatments were greater in sequence B. Additionally, the screening FEV1 was lower in the patients in sequence B compared to sequence $\mathrm{A}$ (mean $3.25 \mathrm{~L}$ versus $4.05 \mathrm{~L}$, respectively $(\mathrm{p}=0.04)$; $81.8 \%$ pred versus $95.5 \%$ pred, respectively $(p=0.014))$. There was no difference in methacholine reactivity or FeNO levels at screening in patients in sequence B compared to sequence $A(p>0.05$ for both comparisons).

There was no effect of OC000459 on the EAR, as the FEV1 AUC and minimum FEV1 were similar to placebo (mean differences $3.8 \%$ (95\% CI $-3.6-11.1 \%$ ) and $2.1 \%$ (95\% CI $-2-6.7 \%$, respectively). Methacholine reactivity at $24 \mathrm{~h}$ post-allergen challenge was similar after treatment with OC000459 compared to placebo; the PC20 was 0.31 compared with $0.39 \mathrm{mg} \cdot \mathrm{mL}^{-1}$, respectively, geometric mean doubling dose difference -0.31 (95\% CI -1.18-0.57).

\section{Pulmonary function and FeNO}

The FEV1 and FeNO measurements before the allergen challenge on days 1,8 and 15 at pre-dose are shown in table 3 . There were no differences between OC000459 and placebo for these parameters.

\section{Induced sputum}

Induced sputum samples that were of adequate cell yield to make cytospins were obtained from 11 patients post-allergen challenge in both treatment periods. The differential cell counts for these 11 patients are shown in table 4 . Eosinophil percentage counts at 1 day post-allergen challenge were lower after treatment with OC000459 compared to placebo, with ratio of geometric means of 0.29 (95\% CI $0.15-0.55, \mathrm{p}=0.002)$. Similar data were observed for eosinophil sputum number per gram: OC000459 adjusted mean $0.4 \times 10^{6}$ cells $\cdot \mathrm{g}^{-1}$ sputum versus placebo adjusted mean $0.75 \times 10^{6}$ cells $\cdot g^{-1}$ sputum $(p=0.002)$. There were no changes in other cell types including lymphocytes. Figure 3 shows the changes in sputum eosinophil percentage by sequence: OC000459 reduced eosinophil counts in both sequences.

\section{Eosinophil shape change}

Eosinophil shape change in response to $\mathrm{PGD}_{2}$ was assessed in seven subjects at day 8. The adjusted mean for AUC of eosinophil shift for OC000459 $(13.4 \% \cdot h)$ was lower than placebo $(47.0 \% \cdot h)$; the mean difference was $-33.6 \% \cdot h$, $(95 \%$ CI $-66.8-$ $-0.4 \% \cdot h), p=0.048$. OC000459 inhibited eosinophil shape change in both sequences (data not shown).

\section{Pharmacokinetics}

The mean $\pm \mathrm{SD}$ plasma OC000459 concentrations were $442 \pm 236 \mathrm{ng} \cdot \mathrm{mL}^{-1}$ at pre-dose on day $8 \quad(\mathrm{n}=16)$ and $560 \pm 421 \mathrm{ng} \cdot \mathrm{mL}^{-1}$ at pre-dose on day $15(\mathrm{n}=16)$. There were

TABLE 3 Pre-dose spirometry

\begin{tabular}{|c|c|c|c|c|c|c|}
\hline & \multicolumn{3}{|c|}{ Placebo } & \multicolumn{3}{|c|}{ OC000459 } \\
\hline & FEV1 L & FEV $1 \%$ pred & FeNO ppb & FEV1 L & FEV $1 \%$ pred & FeNO ppb \\
\hline Day 0 & $3.52 \pm 0.79$ & $85.9 \pm 12.3$ & $39.3 \pm 23.9$ & $3.41 \pm 0.73$ & $82.9 \pm 10.6$ & $33.9 \pm 22.4$ \\
\hline Day 7 & $3.44 \pm 0.82$ & $83.8 \pm 13.4$ & $35.7 \pm 19.2$ & $3.57 \pm 0.72$ & $87.3 \pm 11.7$ & $30.3 \pm 27.2$ \\
\hline Day 15 & $3.36 \pm 0.69$ & $82.1 \pm 11.7$ & $23.3 \pm 22.8$ & $3.41 \pm 0.60$ & $83.6 \pm 10.4$ & $26.3 \pm 23.7$ \\
\hline
\end{tabular}

Data are presented as mean \pm SD. FEV1: forced expiratory volume in $1 \mathrm{~s}$; \% pred: \% predicted; FeNO: exhaled nitric oxide fraction. 


\begin{tabular}{lcc} 
TABLE 4 & $\begin{array}{l}\text { Sputum differential cell counts from paired } \\
\text { samples }\end{array}$ \\
& Placebo & OC000459 \\
\hline & & \\
\hline Total cell count $\times \mathbf{1 0}^{\mathbf{6}} \mathbf{c e l l s} \cdot \mathbf{g}^{-1}$ sputum & $2.03 \pm 1.9$ & $2.36 \pm 2.5$ \\
Neutrophils \% & $44.7 \pm 4.0$ & $59.9 \pm 23.0$ \\
Macrophages \% & $27.7 \pm 20.1$ & $28.3 \pm 4.8$ \\
Eosinophils \% & $18.1(10.0-33.2)$ & $5.6(2.7-11.6)$ \\
Lymphocytes \% & $2.0 \pm 1.9$ & $2.4 \pm 2.5$ \\
\hline & & \\
Data presented as mean \pm SD or geometric mean $\left(95 \%\right.$ Cl). ${ }^{*}: \mathrm{n}=11$.
\end{tabular}

no differences in these OC000459 plasma concentrations due to sequence (data not shown).

\section{DISCUSSION}

The CRTH2 antagonist OC000459 significantly inhibited the LAR in patients with mild asthma. OC000459 also reduced the postallergen sputum eosinophil count. These results indicate that antagonism of CRTH2 by OC000459 inhibits the Th2 inflammatory response after allergen challenge in asthma.

It is known that $\mathrm{PGD}_{2}$ levels are raised in patients with asthma after allergen challenge [3]. Furthermore, targeting this prostanoid using a CRTH2 antagonist in mouse and guinea pig models of asthma inhibits airway inflammation and mucus production $[6,11]$. The current study confirms the role of $\mathrm{PGD}_{2}$ in allergic airway inflammation in humans. OC000459 improved FEV1 in a 28-day study of patients who were not taking inhaled corticosteroids [7]. We now provide further evidence that OC000459 has therapeutic potential as a treatment for allergic asthma.

The primary end-point LAR analysis was performed using both the AUC and maximum percentage change in FEV1 4-10 h after allergen challenge. There was a consistent effect of OC000459 throughout on the LAR as illustrated in figure 1, resulting in a $25.4 \%$ inhibition of the LAR AUC that was statistically significant. The effect of OC000459 on the maximum percentage change was small $(3.9 \%)$ and not statistically significant. The AUC is more representative of the entire LAR time-course, and

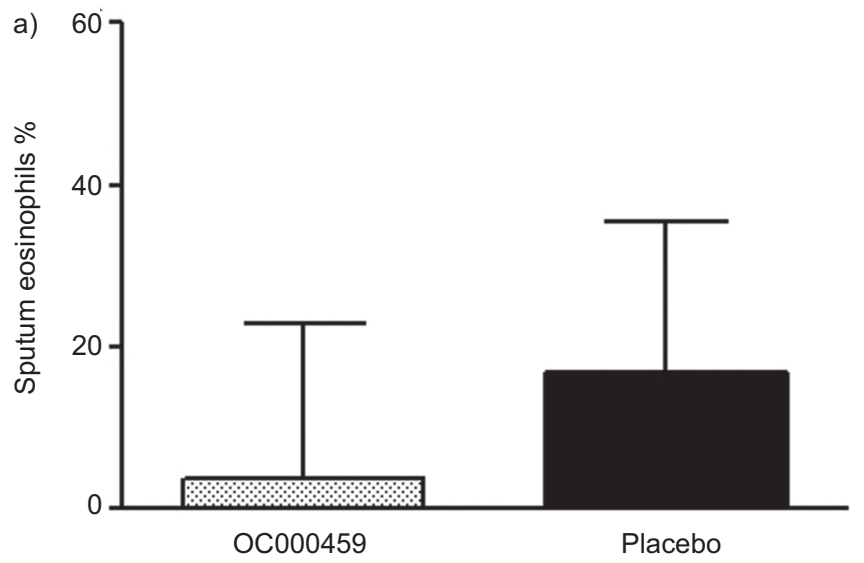

together with the sputum eosinophil data shows an effect of OC000459 on the airway response to allergen challenge.

We observed a period effect for the effect of OC000459 on the LAR, as there was $43 \%$ inhibition of FEV1 AUC in the group of patients receiving placebo first (sequence A), but only $0.9 \%$ when OC000459 was administered first (sequence B). It is unlikely that a carry-over effect caused the sequence B results, as the screening allergen challenge LAR in this sequence was similar to the placebo result. A carry-over effect would have caused a reduced LAR in the placebo period compared with screening. This suggests that OC000459 had no effect on the LAR in sequence B, as the active period AUC was similar to the placebo and screening AUC. Furthermore, the LAR AUC for OC000459 in sequence B was greater than placebo in sequence A, suggesting again no effect of OC000459 on the LAR in sequence B. Any possible carry-over effect was also minimised by the use of a 3-week washout period, which is longer than has been used in other allergen challenge studies [12-14]. Additionally, there are no pharmacokinetic reasons to explain a duration of action of OC000459 after 3 weeks, as the terminal half-life is $13 \mathrm{~h}$ (personal communication) and there are no pharmacologically active metabolites of this drug.

There was no evidence of a period effect for sputum eosinophils or the eosinophil shape-change assay, with OC000459 exerting a therapeutic effect on these end-points for patients in both sequences. This again argues against a carry-over effect in sequence $B$. The period effect on the LAR AUC may be explained by the greater allergic reaction observed in sequence $B$; it is possible that this greater allergic reaction could not be inhibited by OC000459. The patients in sequence B had worse lung function at screening, and it appears that this disease characteristic was associated with a greater response to inhaled allergen, and consequently a reduced effect of OC000459. It should be noted that the study was statistically powered for 16 subjects, and this type of sub-analysis with only eight subjects per group becomes underpowered to assess drug effects. Nevertheless, it is interesting that a period effect was observed for lung function, but not for sputum eosinophils or eosinophil shape change. It has been shown previously that airway eosinophil levels can be reduced by anti-interleukin- 5 therapy without any change in the lung function response to allergen challenge [15]. The lung

b)

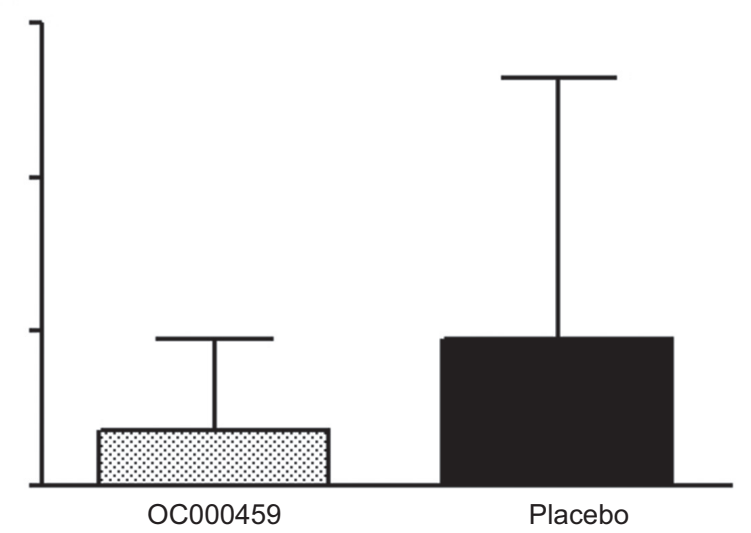

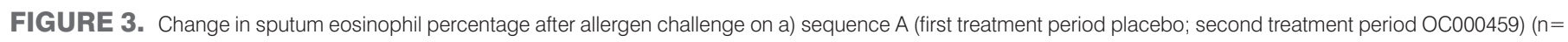
4) and b) sequence B (first treatment period OC000459; second treatment period placebo) $(n=7)$. Data are presented as geometric mean $(95 \% \mathrm{Cl}$ ). 
function response to inhaled allergen is likely to be driven by other cell types, such as mast cells.

The LAR is characterised by a Th2 profile of inflammation with increased numbers of eosinophils, basophils and lymphocytes in the airways [16]. There was a clear inhibitory effect of OC000459 on sputum eosinophil numbers post-allergen challenge. A variety of inflammatory mediators are known to control eosinophil chemotaxis [17]. The current study confirms a significant role for $\mathrm{PGD}_{2}$ in this process within the airways of patients with asthma, as $71 \%$ inhibition of sputum eosinophil percentage from $17.8 \%$ to $5.2 \%$ was achieved with OC000459.

The acute response to allergen exposure, measured by the EAR, is due to mast-cell degranulation [16]. OC000459 had no effect on the EAR, which indicates that CRTH2 activation does not play a significant role in acute bronchoconstriction post-allergen exposure, in keeping with the bronchoconstrictor effects of $\mathrm{PGD}_{2}$ being mediated by the thromboxane receptor, TP [18]. Our results show that $\mathrm{PGD}_{2}$ plays a more significant role in the Th2driven inflammatory cell influx during the LAR, and strategies to combine CRTH2 antagonism with mechanisms that also inhibit bronchoconstriction such as TP or leukotriene antagonism may have greater effect on the allergen challenge response.

The effect of OC000459 on the LAR AUC is similar to both montelukast and the inhaled phosphodiesterase (PDE)-4 inhibitor GSK256066 in studies that we have previously published using the inhaled allergen challenge model [8, 19]. These studies have used the same allergen challenge methodology, allowing some degree of comparison between studies. Comparisons with other studies of drug effects on allergen challenge can be difficult due to differences between challenge methods and the characteristics of the patients. Nevertheless, the effect of OC000459 on the LAR appears to be lower than inhaled corticosteroids [20,21], which perhaps is not surprising given the broad anti-inflammatory effects of corticosteroids on a range of cell types.

The secondary end-point measurement of methacholine challenge post-allergen was not changed by OC000459. The study was not statistically powered for methacholine reactivity, which could explain this negative result. Additionally, previous studies of methacholine reactivity post-allergen challenge have produced contrasting results; for example, inhaled corticosteroids and the leukotriene receptor antagonist montelukast have shown both inhibition and no inhibition of bronchial hyper-reactivity [8, 20-22]. We suggest that the negative results in the current study for methacholine reactivity reflect inadequate sample size with an end-point that is prone to produce variable results.

Exhaled nitric oxide is a biomarker of asthma control, with levels being raised in symptomatic asthma and reduced by inhaled corticosteroids [23]. However, nitric oxide itself does not appear to play a pathophysiological role in asthma, as specific inducible nitric oxide synthase inhibition does not inhibit the allergen challenge response [8]. Furthermore, the effects of antiinflammatory drugs on nitric oxide production varies, as montelukast has variable effects on nitric oxide production [24, 25], while PDE-4 inhibition has no effect on nitric oxide [19]. The current study also indicates that CRTH2 antagonism does not influence nitric oxide levels.
Of the 21 subjects who were enrolled in the study, three subjects were withdrawn due to practical reasons rather than any safety concerns or worsening of symptoms; two of these subjects decided to withdraw consent, while one could not be scheduled in to continue the study. Allergen-challenge studies are time-consuming for trial participants, and so it is not surprising that asthma volunteers sometimes decide not to complete such demanding protocols. We observed no overall pattern of symptom change or adverse events to cause concerns about the safety of this novel drug, compatible with safety data from a 28-day study of OC000459 [7].

The limited pharmacokinetic analysis performed in this study showed stable levels of plasma drug concentrations at $12 \mathrm{~h}$ postdose after 7 and 14 days' dosing. These data indicate adequate systemic exposure to OC000459 using a dosing regimen of $200 \mathrm{mg}$ twice daily. The mean inhibitory concentration (IC50) of OC00459 for inhibition of $\mathrm{PGD}_{2}$-mediated activation of eosinophils in human whole blood is $35 \mathrm{ng} \cdot \mathrm{mL}^{-1}$ (personal communication) and so the plasma levels of drug achieved in this study were well in excess of this level. We also showed that the systemic exposure caused functional antagonism of blood eosinophils ex vivo using a well established eosinophil shape change assay [10]. In phase II studies, blood pharmacokinetic and pharmacodynamic data can be used to help the overall interpretation of the results; for example, if plasma levels were low, and/or the shape change assay results were negative, it could be concluded that systemic exposure and/or activity was insufficient and so pulmonary effects would not be expected. In the current study we observed adequate systemic exposure, coupled with pharmacological activity both in the systemic and pulmonary systems.

In conclusion, we have shown that the CRTH2 antagonist OC000459 inhibits the late-phase allergic response in patients with asthma. This is associated with a reduction in sputum eosinophilia. This study indicates the potential of CRTH2 antagonism as a new therapeutic option for patients with allergic asthma.

\section{SUPPORT STATEMENT}

This study was supported by Oxagen Ltd (Abingdon, UK).

\section{CLINICAL TRIAL}

This study is registered at clinicaltrials.gov with identifier number NCT01056692.

\section{STATEMENT OF INTEREST}

Statements of interest for D. Singh, M. Hunter, L. Pearce Collins, M. Perkins, R. Pettipher, E. Townsend, S. Vinall and B. O'Connor, and for the study itself can be found at www.erj.ersjournals.com/site/misc/ statements.xhtml

\section{REFERENCES}

1 Schleimer RP, Schulman ES, MacGlashan DW Jr, et al. Effects of dexamethasone on mediator release from human lung fragments and purified human lung mast cells. J Clin Invest 1983; 71: 1830-1835.

2 Vinall SL, Townsend ER, Pettipher R. A paracrine role for chemoattractant receptor-homologous molecule expressed on $\mathrm{T}$ helper type 2 cells (CRTH2) in mediating chemotactic activation of CRTH2+ CD4+ T helper type 2 lymphocytes. Immunology 2007; 121: $577-584$ 
3 Murray JJ, Tonnel AB, Brash AR, et al. Release of prostaglandin D2 into human airways during acute antigen challenge. $N$ Engl J Med 1986; 315: 800-804.

4 Hirai H, Tanaka K, Yoshie O, et al. Prostaglandin D2 selectively induces chemotaxis in $\mathrm{T}$ helper type 2 cells, eosinophils, and basophils via seven-transmembrane receptor CRTH2. J Exp Med 2001; 193: 255-261.

5 Royer JF, Schratl P, Carrillo JJ, et al. A novel antagonist of prostaglandin D2 blocks the locomotion of eosinophils and basophils. Eur J Clin Invest 2008; 38: 663-671.

6 Uller L, Mathiesen JM, Alenmyr L, et al. Antagonism of the prostaglandin D2 receptor CRTH2 attenuates asthma pathology in mouse eosinophilic airway inflammation. Respir Res 2007; 8: 16.

7 Barnes N, Pavord I, Chuchalin A, et al. A randomized, doubleblind, placebo-controlled study of the CRTH2 antagonist OC000459 in moderate persistent asthma. Clin Exp Allergy 2012; 42: 38-48.

8 Singh D, Richards D, Knowles RG, et al. Selective inducible nitric oxide synthase inhibition has no effect on allergen challenge in asthma. Am J Respir Crit Care Med 2007; 176: 988-993.

9 Pizzichini E, Pizzichini MM, Efthimiadis A, et al. Indices of airway inflammation in induced sputum: reproducibility and validity of cell and fluid-phase measurements. Am J Respir Crit Care Med 1996; 154: 308-317.

10 Pettipher R, Vinall SL, Xue L, et al. Pharmacologic profile of OC000459, a potent, selective, and orally active D prostanoid receptor 2 antagonist that inhibits mast cell-dependent activation of T helper 2 lymphocytes and eosinophils. J Pharmacol Exp Ther 2012; 340: 473-482.

11 Pettipher R. The roles of the prostaglandin D2 receptors DP1 and CRTH2 in promoting allergic responses. Br J Pharmacol 2008: 153; S191-S199.

12 Perry TT, Corren J, Philip G, et al. Protective effect of montelukast on lower and upper respiratory tract responses to short-term cat allergen exposure. Ann Allergy Asthma Immunol 2004; 93: 431-438.

13 van Schalkwyk E, Strydom K, Williams Z, et al. Roflumilast, an oral, once-daily phosphodiesterase 4 inhibitor, attenuates allergeninduced asthmatic reactions. J Allergy Clin Immunol 2005; 116: 292-298.
14 Norris V, Choong L, Tran D, et al. Effect of IVL745, a VLA-4 antagonist, on allergen-induced bronchoconstriction in patients with asthma. J Allergy Clin Immunol 2005; 116: 761-767.

15 Leckie MJ, ten Brinke A, Khan J, et al. Effects of an interleukin-5 blocking monoclonal antibody on eosinophils, airway hyperresponsiveness, and the late asthmatic response. Lancet 2000; 356: 2144-2148.

16 O'Byrne PM. Allergen-induced airway inflammation and its therapeutic intervention. Allergy Asthma Immunol Res 2009; 1: 3-9.

17 Hogan SP, Rosenberg HF, Moqbel R, et al. Eosinophils: biological properties and role in health and disease. Clin Exp Allergy 2008; 38: 709-750.

18 Coleman RA, Sheldrick RLG. Prostanoid-induced contraction of human bronchial smooth muscle is mediated by TP-receptors. $\mathrm{Br} \mathrm{J}$ Pharmacol 1989; 96: 688-692.

19 Singh D, Petavy F, Macdonald AJ, et al. The inhaled phosphodiesterase 4 inhibitor GSK256066 reduces allergen challenge responses in asthma. Respir Res 2010; 11: 26.

20 Cockcroft DW, Murdock KY. Comparative effects of inhaled salbutamol, sodium cromoglycate, and beclomethasone dipropionate on allergen-induced early asthmatic responses, late asthmatic responses, and increased bronchial responsiveness to histamine. J Allergy Clin Immunol 1987; 79: 734-740.

21 Palmqvist M, Bruce C, Sjöstrand M, et al. Differential effects of fluticasone and montelukast on allergen-induced asthma. Allergy 2005; 60: 65-70.

22 Davis BE, Cockcroft DW. Effect of a single dose of montelukast sodium on methacholine chloride PC20. Can Respir J 2005; 12: 26-28.

23 Pérez-de-Llano LA, Carballada F, Castro Añón O, et al. Exhaled nitric oxide predicts control in patients with difficult-to-treat asthma. Eur Respir J 2010; 35: 1221-1227.

24 Fritscher LG, Rodrigues MT, Zamel N, et al. The effect of montelukast on exhaled nitric oxide of alveolar and bronchial origin in inhaled corticosteroid-treated asthma. Respir Med 2009; 103: 296-300.

25 Gelb AF, Taylor CF, Shinar CM, et al. Effect of fluticasone $250 \mu \mathrm{g} /$ salmeterol $50 \mu \mathrm{g}$ and montelukast on exhaled nitric oxide in asthmatic patients. Can Respir J 2008; 15: 193-198. 